\title{
Study on Selective Pyrolysis of Biomass for Production of Upgraded Bio-Oil
}

\author{
Xiaoning Ye ${ }^{1}$, Xuejiao Lei ${ }^{1}$, Caixia Wang ${ }^{1}$, Qionghui Li $^{1}$, Wei Yuan ${ }^{1}$ and Ziqian Li ${ }^{1}$ \\ ${ }^{1}$ State Grid Energy Research Institute Co. LTD Beijing, China
}

\begin{abstract}
Biomass fast pyrolysis liquefaction to obtain biological oil is a mixture of water and hundreds of organic compounds, can be used as liquid fuel or chemical raw materials used in different fields. In order to increase the application value of the bio-oil, on the one hand, the biological oil can be refined, on the other hand can target specific biomass raw materials, selective control pyrolysis reaction process, thereby gaining specific high grade oil. With the improvement of catalyst preparation, a variety of new king of catalysts were introduced to the field of biomass pyrolysis. Recently, some researches had reported that some chemicals can be selectively promoted by introducing specific technology during pyrolysis process. Using this technology, chemical-riched liquid would be produced and the following purification process would be greatly simplified. Hence, developing new kind of technique with high selectivity to realize a variety of chemical preparation will be an inexorable trend in the field of biomass pyrolysis.
\end{abstract}

\section{Introduction}

In order to produce certain types of specific energy or platform compounds, it is necessary to exercise targeted control over the process of biomass pyrolysis, as a way to obtain target products and prevent the generation of other organic liquid products. This is how we can achieve a high concentration of target products in the liquid products, which proves beneficial to separation and purification[1-3]. This kind of pyrolysis is called selective pyrolysis of biomass. In recent years, various researchers, in regards to biomass or its basic components (cellulose, hemicellulose and lignin), have been trying to improve the pyrolysis process to regulate the distribution of pyrolysis products through various means such as pretreatment of raw materials, optimization of pyrolysis conditions and catalysts[4-6]. Compared with traditional pyrolysis of biomass to produce solid coke (carbonization technology), liquid bio-oil (liquefaction technology) or combustible mixtures (gasification technology), selective pyrolysis of biomass, as a cutting-edge technology of efficiently utilizing biomass, can produce upgraded and high-value products, and contribute to a wider field of application[7-9]. Therefore, it is receiving increasingly more attention from a large number of scientists at home and abroad for its bright market prospects and economic and social benefits.

At present, some new products have been produced through this technology, especially for furfural (FF) and levoglucosenone (LGO).

\section{Production of High-Value Chemicals}

\subsection{Furaldehyde}

\subsubsection{Introduction of Furaldehyde (FF)}

Furaldehyde, furfural or FF for short, is a derivative from the reaction in which the hydrogen atom at the 2position of the furan is substituted with the aldehyde group, with the molecular formula $\mathrm{C}_{5} \mathrm{H}_{4} \mathrm{O}_{2}$-also known as 2-furaldehyde. It is not only the most important furan ring derivative, but also one of the main pyrolytic products of cellulose and hemicellulose. FF is formed from dehydration after bond cleavage and ring scission in the elementary unit of cellulose. Aside from this, it can also be produced through the depolymerization of xylan and its bond cleavage as well as the detachment of the substituent group in hemicellulose. FF is mainly used in the industry as an organic solvent and an intermediate in synthetic perfumes, furfuryl alcohol and oxolane.

\subsubsection{Characteristics of Production of FF from Cellulose Pyrolysis}

Because of the complex chemical composition of biomass, cellulose used as a raw material to study the production of FF through pyrolysis at the incipient stage. After that, many studies carried out to examine the characteristics of the formation of $\mathrm{FF}$ during the process. As one of the important products of cellulose pyrolysis, the formation of FF influenced by many factors, including pyrolysis time, temperature and other factors. Following numerous studies, researchers have found that cellulose begins to produce $\mathrm{FF}$ at about $300^{\circ} \mathrm{C}$, and more

\footnotetext{
* Corresponding author: yexiaoning@sgeri.sgcc.com.cn
} 
FF can be made as the temperature rises, with maximum productivity reached at $550^{\circ} \mathrm{C}-650^{\circ} \mathrm{C}$. Meanwhile, increasing the pyrolysis time can also speed up the pyrolysis of cellulose to produce $\mathrm{FF}$ and improve its productivity.

In the process of fast pyrolysis, cellulose undergoes depolymerization, ring scission and $\mathrm{C}-\mathrm{C}$ bond, before $\mathrm{FF}$ is formed by $\mathrm{C} 1-\mathrm{C} 5$ or $\mathrm{C} 2-\mathrm{C} 6$ acetal and dehydration, as shown in Fig.1.

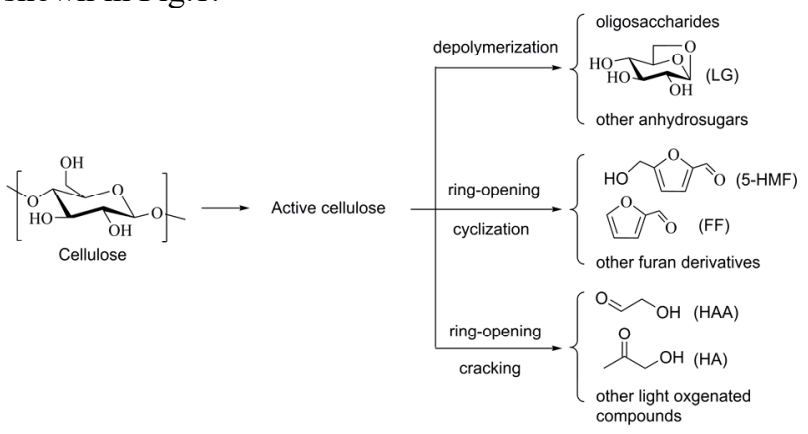

Fig. 1 Fast Pyrolysis of Cellulose to Produce FF

Using pure cellulose as a raw material, Lu studied the effect of temperature and time on the formation of FF by Py-GC/MS. The results revealed that the absolute content of $\mathrm{FF}$ at temperatures ranging from $300^{\circ} \mathrm{C}$ to $550^{\circ} \mathrm{C}$ showed a sharp rise with the increase of temperature and time, but increased steadily after $600^{\circ} \mathrm{C}$. The relative content of FF, however, decreased with the increase in temperature and pyrolysis time.

\subsubsection{Characteristics of Production of FF from Biomass Pyrolysis}

With the development of research, many kinds of biomass containing cellulose and hemicellulose are used as raw materials to study the formation of FF. There are more than 100 types of biomass known for fast pyrolysis, including agricultural and forestry waste, energy crops, solid waste and leather waste, according to A.V. Bridgwater. The FF can be produced using biomass containing cellulose and hemicellulose by fast pyrolysis, but the productivity levels are different. In addition, various factors affect the production of FF, including interaction between cellulose and lignin, the acceleration of the heating rate and the increase of particle size in raw materials within a certain range.

A study was performed on the effect of interaction among cellulose, hemicellulose and lignin in biomass by TG-FTIR. The results showed that the interaction between cellulose and lignin is conducive to the formation of FF. In addition, some researchers also found that the heating rate and size of the raw material have a certain impact on the productivity of FF. In the Encinar study, the raw materials of olive and grape were placed in a self-made pyrolytic reactor which was controlled at $500^{\circ} \mathrm{C}$ and $200 \mathrm{ml} / \mathrm{min}$, with varying particle sizes $(0.4-2.0 \mathrm{~mm})$. It was found that with the increase of particle size, the productivity of FF increased gradually, with the maximum reached at $2 \mathrm{~mm}$. Therefore, the authors of the study argue that with the increase in particle size, the time for the temperature in the particles to rise to the final reaction is prolonged, so that the inner particle is pyrolyzed at a relatively low temperature. Different from other products, the pyrolysis of FF occurs at a relatively low temperature, which contributes to the gradual increase in productivity.

\subsubsection{Production of FF from Selective Pyrolysis of Cellulose or Biomass}

As a high-value chemical, FF is widely used in the fields of medicine and chemistry. High-purity FF, if produced, stands to benefit the economy and society. Therefore, many researchers are committed to increasing the productivity of FF. The addition of catalyst can better selectively control the production of FF from pyrolysis. There are many kinds of catalysts which can be used in the field of biomass, including acid catalysts, basic catalysts, zeolite catalysts, metal oxides, metal salts, various home-made catalysts and so on.

It can be found in the existing literature that using phosphorus-containing compounds as a catalyst can facilitate tpyrolysis to form FF. According to Nowakowski, the treated miscanthus hemicellulose and hemicellulose with added $\mathrm{H}_{3} \mathrm{PO}_{4}$ or $\left(\mathrm{NH}_{4}\right)_{3} \mathrm{PO}_{4}$ can remarkably improve the productivity of FF.

Moreover, other metal oxides, salts and acids also have had some effect on productivity. In a study conducted by Branca, the selective pyrolysis of cornstalks was carried out, in a packed-bed reactor, to produce FF using acid and metal chloride as catalysts, respectively. During the process, Branca conducted an experiment of pyrolysis to compare washed cornstalks to unwashed ones. He found that there was little difference in terms of formation of FF between the yield of FF was $0.59 \mathrm{wt} \%$ from unwashed cornstalks and $0.65 \mathrm{wt} \%$ from the washed ones, indicating that the ash content of the cornstalk has little effect on the production of FF.

\subsubsection{Sub-summary}

Today, FF is widely used in various areas, including in oil refineries, plastics, food, medicine, agriculture and other industries. As a kind of clean energy, and because of its variety, biomass used to produce FF from pyrolysis of biomass has been widely recognized in agricultural China. Therefore, in the future, the production of highvalue chemicals by changing different reaction conditions and using effective catalysts through selective pyrolysis of biomass will become popular.

\subsection{5-Hydroxymethylfurfural}

\subsubsection{Brief Introduction of 5-hydroxymethylfurfural (HMF)}

5-hydroxymethylfurfural is also known as 5hydroxymethyl-2-furfural, 5-hydroxymethyl-furfural or 5-HMF, with molecular formula $\mathrm{C}_{6} \mathrm{H}_{6} \mathrm{O}_{3}$. Most of $\mathrm{HMF}$, a six-carbon-atom furan compound, can be found in 
cellulose. The key in the pyrolysis to produce HMF rests in the cleavage of the $\mathrm{C} 1-0$ bond, the dehydration of the molecule and the formation of the furan ring through the acetals between $\mathrm{C} 2$ and $\mathrm{C} 5$. In addition, HMF is also an important chemical raw material. Because it contains an aldehyde group and a hydroxymethyl group in its molecule, it can be used to synthesize many useful compounds and high polymer materials through hydrogenation, oxydehydrogenation, esterification, halogenation, polymerization, hydrolyzation and other chemical reactions.

\subsubsection{Characteristics for Production of HMF from Cellulose/Hemicellulose/Biomass Pyrolysis}

(1) Production of HMF from Cellulose Pyrolysis

Because of the complex chemical composition of biomass, cellulose is used as a raw material in the study of the production of HMF through pyrolysis at the incipient stage. Following that, many studies have been carried out to examine characteristics about its formation during the process. As one of the important products of cellulose pyrolysis, the formation of HMF is influenced by many factors, including pyrolysis time and temperature.

Following examination by many researchers of the HMF produced by pyrolysis using cellulose and other materials, a method has been developed as follows. The cleavage of the glycosidic $\mathrm{C} 1$ bond and the $\mathrm{C} 1-0$ chemical bond acetal causes the pyran ring scission, which further leads to acetal, dehydration, cleavage of the glycosidic $\mathrm{C} 4$ bond and other reactions, before the HMF is finally formed. As the cleavage of the glycosidic $\mathrm{C} 4$ bond may occur during different times in the process, there are many possible ways to form HMF in the process of cellulose pyrolysis.

With the improvement of pyrolysis technology, a study was carried out to examine the formation of HMF using cellulose in a self-made pyrolysis reactor at $430^{\circ} \mathrm{C}$ $-730^{\circ} \mathrm{C}$ for $0.44-1.32 \mathrm{~s}$. It was found that the maximum productivity of $\mathrm{HMF}$ was $3.54 \%$ at $630^{\circ} \mathrm{C}$ and $0.44 \mathrm{~s}$. Based on this, Shen proposed a possible method for the production of HMF, HAA and LG from cellulose pyrolysis, as shown in Fig. 2. In addition, Lu used pure cellulose to study the effect of temperature and time on the formation of $\mathrm{HMF}$ by $\mathrm{Py}-\mathrm{GC} / \mathrm{MS}$. The results revealed that $\mathrm{HMF}$ yield increased significantly with the temperature rising from $400^{\circ} \mathrm{C}$ to $550^{\circ} \mathrm{C}$, but showed an unremarkable increase after $600^{\circ} \mathrm{C}$, with maximum productivity reached at $550^{\circ} \mathrm{C}$.

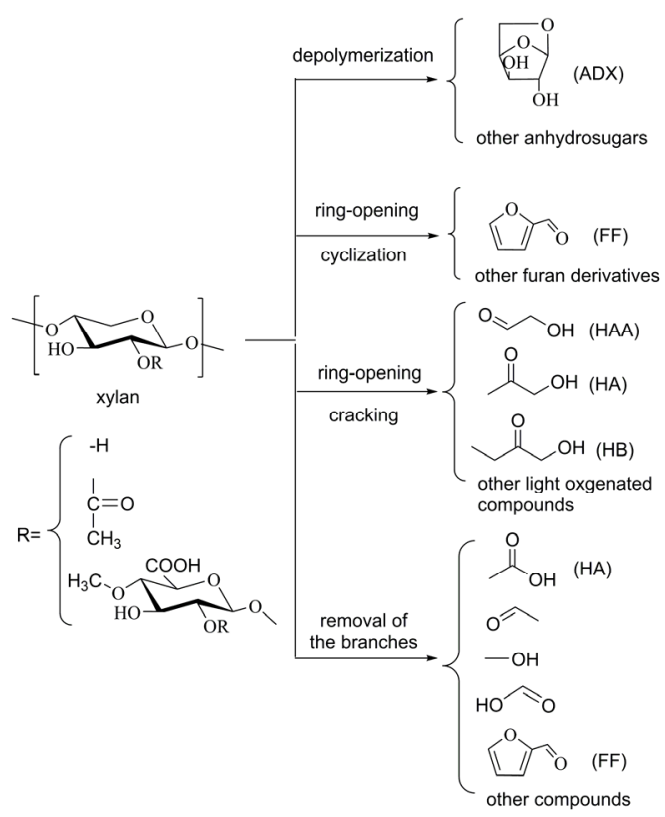

Fig. 2 Main Reaction Pathways of Fast Cellulose Pyrolysis

Because the reactions of ring scission and depolymerization occur simultaneously in the cellulose pyrolysis, some researchers wondered whether monosaccharides with no degree of polymerization or sugars and a low degree of polymerization could be employed to produce large amounts of HMF. Therefore, fructose used as a raw material for fast pyrolysis at a lower temperature to form HMF as the main product. It found that the productivity of $\mathrm{HMF}$ increased first and then decreased at $250{ }^{\circ} \mathrm{C}-500^{\circ} \mathrm{C}$, with the maximum reached at $350^{\circ} \mathrm{C}$. The results showed that when the temperature was lower than $350^{\circ} \mathrm{C}$, the pyrolysis of fructose was not complete. Therefore, increasing temperature could promote its pyrolysis and improve the productivity of the $\mathrm{HMF}$, and maximum productivity reached at $350^{\circ} \mathrm{C}$.

(2) Production of HMF from Hemicellulose Pyrolyzsis

Little research on HMF from hemicellulose pyrolysis has been carried out, because the main composition of hemicellulose is xylan, which is a five-carbon-atom sugar, unable to form HMF when pyrolyzed. Only a small amount of grape-mannan and polygalactose in it can produce HMF. This is because the structure similar to cellulose, so HMF formed by pyrolysis. It also verified by using galactose as a raw material.

(3) Production of HMF from Biomass Pyrolyzsis

HMF formation from biomass pyrolysis is different compared to that of cellulose. Because there are other components in the biomass, the amount of HMF produced by biomass pyrolysis increases first and then decreases as temperature and time increase. Similar to cellulose pyrolysis, the maximum productivity of $\mathrm{HMF}$ from biomass pyrolysis reached at $550^{\circ} \mathrm{C}-600^{\circ} \mathrm{C}$.

Poplar wood used as biomass material to study $\mathrm{HMF}$ formation during pyrolysis at $300^{\circ} \mathrm{C}-1000^{\circ} \mathrm{C}$ for between 5 and 30 seconds. The results showed that both yield and productivity of HMF increased first and then decreased with the rising of temperature, peaking at $550^{\circ} \mathrm{C}$, which 
is different from that of pure cellulose. The effect of pyrolysis time on the production of HMF is not significant at low temperatures. The $\mathrm{LG}$ content reached the maximum at $500^{\circ} \mathrm{C}-600^{\circ} \mathrm{C}$ for 20 seconds, indicating that the materials were pyrolyzed at 20 seconds. Further increase of time, however, had little effect on $\mathrm{HMF}$ formation. When the temperature is above $600^{\circ} \mathrm{C}$, the longer the time is, the lower the productivity of $\mathrm{HMF}$ is, resulting from secondary pyrolysis of $\mathrm{HMF}$ at $600^{\circ} \mathrm{C}$.

In the studies mentioned above, the researchers found that aside from the traditional three components of biomass, there is also a small amount of ash impacting the process and HMF productivity. In one particular study, cellulose was used with the addition of $10 \mathrm{wt} \%$ $\mathrm{ZnCl}_{2}$ or $\mathrm{K}_{2} \mathrm{CO}_{3}$ to produce HMF. It was found that the relative content of HMF $(1.39 \%)$ by pyrolysis of cellulose without being impregnated with metal salts was twice as high as that of raw materials impregnated with $\mathrm{ZnCl}_{2}(0.69 \%)$ or $\mathrm{K}_{2} \mathrm{CO}_{3}(0.70 \%)$, implying that these two metal salts inhibited HMF formation. Following that, a further study on the influence of eight inorganic substances $\left(\mathrm{NaCl}, \mathrm{KCl}, \mathrm{MgCl}_{2}, \mathrm{CaCl}_{2}, \mathrm{Ca}(\mathrm{OH})_{2}\right.$, $\left.\mathrm{Ca}\left(\mathrm{NO}_{3}\right)_{2}, \mathrm{CaCO}_{3}\right)$ in ash content over $\mathrm{HMF}$ formation was conducted. Moreover, the formation of HMF more or less inhibited by other inorganic substances.

\subsubsection{Production of HMF by Cellulose/Biomass Selective Pyrolysis}

As a high-value chemical, HMF is widely used in the medicine and chemical industries. If high purity HMF can be produced, its production would bring great benefit to the economy and society. Therefore, many researchers have been working to improve the productivity of HMF in the pyrolysis process. At present, the main methods to produce HMF from biomass include direct pyrolysis, pyrolysis after biomass is treated and catalytic pyrolysis.

It can be determined in the existing literature that using phosphorus-containing compounds as a catalyst can facilitate pyrolysis to form FF. According to Nowakowski, treated miscanthus hemicellulose and hemicellulose which are impregnated with $\mathrm{H}_{3} \mathrm{PO}_{4}$ or $\left(\mathrm{NH}_{4}\right)_{3} \mathrm{PO}_{4}$ can remarkably improve the productivity of FF. $\mathrm{ZnCl}_{2}$ used as a catalyst for the pyrolysis of biomass was carried out to explore its effect on HMF formation. The results showed that the yield of HMF increased first and then decreased with the increased loading of $\mathrm{ZnCl}_{2}$, and the maximum productivity of HMF was $3 \%$ with a loading amount of $5 \mathrm{wt} \%$. When it exceeded $20 \mathrm{wt} \%$, the formation of HMF was completely inhibited.

The productivity of HMF can be increased selectively by adding a proper catalyst, which costs more and makes the experiment more difficult. However, it is the easiest and most cost-effective method to produce HMF using special biomass materials. The difficulty we now face is that a vast number of biomass materials need to be screened for pyrolysis. $\mathrm{Lu}$ found that at low temperatures, such as $350^{\circ} \mathrm{C}$ in cornstalk pyrolysis, a large amount of HMF could be formed. The results revealed that HMF could easily be produced from cornstalks, contributing a new way for the selective pyrolysis and liquefaction of biomass to produce HMF.

\subsubsection{Sub-summary}

Nowadays, HMF, a new platform compound based on biomass resources, has been widely used across many fields. For example, they can be employed to the synthesis of medicine, resin plastics, diesel fuel additives and high-value products including Furan-2, 5dicarbaldehyde, 2, 5-Furandicarboxylicacid and laevulinic acid. At present, the method of producing HMF is mainly via hydrolysis, but great potential in pyrolysis can be unleashed in the future. Therefore, in the future, there is certain to be a trend of producing high-value chemicals by using special biomass, changing different reaction conditions and adding proper catalysts through selectively pyrolysisi.

\section{Conclusion}

In order to produce upgraded liquid products, great attention across the globe has been paid to adding catalysts in the fast pyrolysis process to selectively control the reaction pathway or product as a way of producing high-grade fuel oil or high-value bio-oil. In recent years, some studies have found that adding specific catalysts in the pyrolysis process can promote the formation of chemicals in a selective way, and the concentration of chemicals in liquid products can also be achieved through this technology, making the separation and purification process easier. However, as far as we know, there are limited chemicals for selective concentration, and most of them are cellulose derivatives. Therefore, developing new catalysts for the selective production of a variety of chemicals through biomass pyrolysis will prove a defining trend.

\section{Acknowledgements}

This work is supported by State Grid Corporation Science and Technology Project (New Energy Optimization Development Criteria, Analysis Technology and Application Research for High Proportional Grid-to-Net Consumption, 4000201933192A-0-0-00). The authors thanks State Grid Gansu Electric Power Supply Company for funding the project.

\section{References}

1. Demirbas, A., Arin, G. An overview of biomass pyrolysis[J]. Energy Sources, 2002, 24: 471-482

2. A.V. Bridgwater, Review of fast pyrolysis of biomass and product upgrading $[\mathrm{J}]$. Biomass and Bioenergy. 2012, 38:68-94

3. A. V. Bridgwater, G. V. C. Peacocke. Fast pyrolysis processes for biomass[J]. Renewable \& Sustainable Energy Reviews, 2000, 4 (1): 1-73. 
4. D. K. Shen, S. Gu. The mechanism for thermal decomposition of cellulose and its main products[J]. Bioresource Technology, 2009, 100 (24): 6496-6504.

5. Q. Lu, W.M. Xiong, W.Z. Li, et al. Catalytic pyrolysis of cellulose with sulfated metal oxides: a promising method for obtaining high yield of light furan compounds[J]. Bioresour. Technol, 2009, 100 (20): 4871-4876.

6. Lu, Q., Dong, C., Zhang, X., et al. Selective fast pyrolysis of biomass impregnated with $\mathrm{ZnCl} 2$ to produce furfural: Analytical Py-GC/MS study[J]. Journal of Analytical and Applied Pyrolysis, 2011, $90: 204-212$

7. Q. Lu, W.M. Xiong, W.Z. Li, et al. Catalytic pyrolysis of cellulose with sulfated metal oxides: a promising method for obtaining high yield of light furan compounds[J]. Bioresour. Technol, 2009, 100 (20): 4871-4876.

8. D. K. Shen, S. Gu. The mechanism for thermal decomposition of cellulose and its main products[J]. Bioresource Technology, 2009, 100 (24): 6496-6504.

9. C. Q. Dong, Z. F. Zhang, Q. Lu, et al. Characteristics and mechanism study of analytical fast pyrolysis of poplar wood[J]. Energy Conversion and Management, 2012, 57 49-59. 